\title{
DESENVOLVIMENTO E AVALIAÇÃO DE USABILIDADE DE SOFTWARE PARA PESQUISA DE PÚBLICOS NO MUSEU CÂMARA CASCUDO
}

\author{
SOFTWARE DEVELOPMENT AND USABILITY EVALUATION FOR \\ RESEARCH ON CAMMARA CASCUDO MUSEUM VISITORS
}

\author{
Pedro Gabriel Silva de Lima ${ }^{1}$, Graduando, pedrogab96@gmail.com \\ Marina Pereira Farias do Amaral ${ }^{1}$, Bach., marinaamaral02@gmail.com \\ Bruno Santana da Silva ${ }^{1}$, D.Sc., bruno@imd.ufrn.br, http://orcid.org/0000-0002-7689-8000
}

\author{
${ }^{1}$ Universidade Federal do Rio Grande do Norte, Natal, Brasil
}

pesquisa de público, avaliação da interface, mcc, teste de usabilidade

\begin{abstract}
Museus buscam estabelecer comunicações eficientes e eficazes com seus públicos. A pesquisa de público precisa fazer parte do cotidiano dos museus e não apenas em atividades esporádicas, pois seus públicos estão em constante evolução. Amaral (2019) projetou um software para coletar dados sobre os perfis dos públicos que visitam o Museu Câmara Cascudo e facilitar a condução contínua da pesquisa de público nesse museu. Como continuidade, este trabalho apresenta o desenvolvimento deste software e sua avaliação com a participação de visitantes do museu dentro do setor expositivo. Buscou-se desenvolver um software flexível para uso em diferentes dispositivos, de fácil atualização das questões de pesquisa e com resultados salvos para facilitar diferentes análises futuras. O software foi avaliado por um teste de usabilidade que analisou a conclusão da coleta de dados, o tempo necessário, dúvidas e desconfortos dos visitantes em relação às perguntas. Todos os 11 participantes conseguiram completar a tarefa com sucesso, em média de 3 minutos. Alguns participantes enfrentaram dificuldades relacionadas com a familiaridade com a tecnologia. Essas dificuldades foram facilmente superadas, sem impacto significativo para a experiência do visitante. Este software demonstrou ser uma ferramenta com potencial para apoiar a pesquisa de públicos no museu de forma contínua.
\end{abstract}

visitors research, user interface evaluation, mcc, usability test

Museums seek to establish efficient and effective communications with their different visitors. Audience survey needs to be part of museums daily life and not just sporadic activities, because their audiences are constantly evolving. Amaral (2019) designed a software to collect data about visitors' profiles of the Câmara Cascudo Museum and facilitate continuous audience survey execution in this museum. As a continuity, this work presents the development of this software and its evaluation with the participation of museum visitors within the exhibition sector. The developed software is flexible for use on different devices, with easy updating of survey questions, and with saved results to facilitate different future analyzes. The software was evaluated with a usability test that analyzed completion of data collection, time required, visitors' doubts and discomforts regarding questions. All of the participants successfully completed the task, in 3 minutes on average. Some participants faced difficulties related to familiarity with technology. These difficulties were easily overcome, with no significant impact on the visitor's experience. The software was validated as a tool with potential to support continuous audience survey at the Câmara Cascudo Museum. 


\section{Introdução}

Museus são tradicionalmente espaços expositivos e contemplativos. Aos poucos eles também vêm se tornando ambientes de comunicação, reflexão e de produção de conhecimento para todos, sejam visitantes em geral ou a comunidade científica (BORGES et al., 2012; BOYLAN, 2004). Os novos papéis que os museus estão assumindo requerem maior diálogo com a sociedade para que eles possam oferecer serviços mais adequados e estabelecer boas relações com seus diferentes públicos.

A comunicação efetiva e eficaz dos museus com seus públicos é uma atividade fundamental nessa nova realidade. Entretanto, ela ainda é um desafio para essas instituições, pois para um ato comunicativo ocorrer bem, os interlocutores precisam conhecer um pouco sobre quem os ouve (CURY, 2005; 2015). Os museus então precisam conhecer seus públicos para terem condições necessárias para estabelecer comunicações e relacionamentos de qualidade com eles. Em geral, não é possível caracterizar os visitantes de museus como um único grupo estático, pois eles compartilham de diferentes características sociais, econômicas, educacionais e culturais que mudam com o tempo e implicam em diferenças significativas no perceber, interpretar, pensar, agir e interagir. Essa diversidade de públicos não deveria ser ignorada já que expõe os museus a um maior risco de desgaste e obsolescência (CÂNDIDO, 2014).

Avaliações ou pesquisas sobre os públicos ajudam os museus a definirem adequadamente como devem prosseguir seu trabalho no curto, médio e longo prazo (CURY, 2005). Elas fornecem subsídios para elaboração de estratégias que atraiam os públicos atuais e novos públicos (o não público), tanto em relação aos serviços oferecidos (exposições, eventos, etc.), quanto em relação à divulgação adequada para a sociedade. Os públicos de museus mudam com o tempo, acompanhando as dinâmicas sociais, culturais e econômicas da sociedade, bem como as dinâmicas próprias dos museus (reformas, gestão, etc.). Portanto, a pesquisa de públicos deve ser uma atividade contínua para subsidiar uma gestão adequada dos museus. Para isso ser viável na prática cotidiana de museus, a coleta e a análise de dados sobre os públicos de museus precisam ser rápidas e de baixo custo.

Num esforço de melhorar sua gestão e continuar oferecendo serviços de qualidade, o Museu Câmara Cascudo (MCC) da Universidade Federal do Rio Grande do Norte (UFRN) tem se preocupado em conhecer melhor seus públicos. Suas pesquisas de públicos têm sido eventuais e ainda podem apoiar melhor a gestão do museu. Estas pesquisas não costumam ser realizadas com frequência porque a coleta e a análise de dados são completamente manuais com apoio de ferramentas analógicas e não integradas, exigindo tempo e recursos consideráveis. Tipicamente um questionário em papel é preenchido; seus dados são manualmente inseridos em uma tabela; para então realizar-se análise manual de muitos dados obtidos.

Amaral (AMARAL, 2019; AMARAL et al., 2021) investigou como as Tecnologias de Informação e Comunicação (TICs) poderiam contribuir com a pesquisa contínua dos perfis de públicos no MCC. Como resultado, ela apresentou o projeto de um software para coletar dados dos visitantes deste museu, através de um questionário. Quando os dados coletados estiverem em meio digital, eles podem ser fácil e eficientemente analisados com apoio de ferramentas computacionais de processamento e visualização de informações, diferente dos dados coletados por meios analógicos anteriormente no MCC que requerem muito trabalho. O projeto de Amaral (AMARAL, 2019; AMARAL et al., 2021) foi apresentado em um protótipo navegável de alta fidelidade elaborado no Adobe XD. Ele permitiu realizar uma avaliação somativa (BARBOSA; SILVA, 2010) que indicou grande potencial para esta solução para uso contínuo no MCC.

Em continuidade ao trabalho de Amaral (2019), este trabalho apresenta o desenvolvimento do software projetado, bem como uma avaliação dele com a participação dos visitantes do museu in loco. 


\section{Pesquisa de Públicos em Museus}

A pesquisa de públicos faz parte da agenda recente de pesquisa em Museologia no Brasil por possuir papel importante na gestão de museus (KÖPTCKE, 2012; CUTRIM, 2014; CURY, 2015). Além de permitir que os museus conheçam quem os visita e, por complemento, quem não os visita, a pesquisa de públicos também permite verificar se os serviços museológicos oferecidos atendem às expectativas dos seus públicos (PAULA, 2013). Essa pesquisa pode ter diferentes objetivos, tais como: compreender os perfis dos visitantes, entender a dinâmica da visitação dentro dos espaços do museu e compreender a opinião dos visitantes sobre a experiência de visitação e suas interpretações sobre o discurso museológico (KÖPTCKE, 2012). Este trabalho tem como foco a pesquisa sobre os perfis dos públicos visitantes de museus.

A literatura relata várias pesquisas de perfis de visitantes em museus (BRAGA, 2002; ALMEIDA, 2004; GUAPO, 2009; CORREAA, 2010; JUNIOR; KUPERMAN, 2012; COIMBRA et al., 2014; SILVA; SILVA, 2015). Apesar de serem iniciativas importantes, estes foram esforços pontuais que geralmente não se repetiram ao longo da gestão dos respectivos museus. Uma das prováveis razões para isso ocorrer deve-se ao fato de que as atividades de coleta, análise e relato de resultados sobre os perfis de públicos serem trabalhosas e demoradas. Deste modo, existe demanda para desenvolver maneiras de facilitar a execução regular de pesquisas de público em museus, em particular na realidade brasileira.

A sociedade tem utilizado as Tecnologias da Comunicação e Informação (TICs) para viabilizar e facilitar a manipulação de volume e diversidade cada vez maior de informações em diferentes áreas. Em museus, as TICs têm sido utilizadas principalmente para enriquecer as experiências de visitação e os relacionamentos com seus públicos (DROTNER; SCHRØDER, 2013). Contudo, elas ainda são pouco utilizadas para apoiar a pesquisa de públicos em museus.

Na realidade brasileira, um único trabalho foi encontrado na literatura sobre o uso das TICs para coletar dados de pesquisa de públicos em museus. Studart et al. (2007) desenvolveram um software para apoiar a pesquisa de públicos para o Museu da Vida da Fiocruz, no Rio de Janeiro. Esta pesquisa de públicos teve por objetivo avaliar a experiência de visitação no museu, sem abordar os perfis dos seus públicos. Este trabalho parece não ter sido continuado, pois os autores não tiveram outras publicações sobre este software e ele também não é mais referenciado no site da instituição atualmente.

\section{Projeto de Interface do Software de Pesquisa de Público}

Diante do potencial das TICs como facilitador das pesquisas de públicos de museus e da carência de softwares com esse fim, Amaral (AMARAL, 2019; AMARAL et al., 2021) projetou a interface de um software para coletar dados sobre os perfis de públicos do Museu Câmara Cascudo. Conforme apresentado no Quadro 1, sua solução possui quinze perguntas com as respectivas opções de respostas (AMARAL, 2019, p. 37-39).

\footnotetext{
1. Você se considera? Homem, Mulher e Outros.

2. Qual a sua idade? 10 a 14 anos, 15 a 19 anos, 20 a 29 anos, 30 a 39 anos, 40 a 49 anos, 50 a 59 anos, 60 a 64 anos e Mais de 65 anos.

3. Em qual país você mora? Brasil e Informe outro país.

4. Em qual cidade você mora? Selecione cidade - estado.

5. Você se considera da etnia ou cor? Amarelo, Branco, Indígena, Negro, Pardo e Outros.

6. Qual o seu nível de escolaridade? Ensino fundamental incompleto, Ensino fundamental completo, Ensino médio incompleto, Ensino médio completo, Ensino superior incompleto, Ensino superior completo e Pós-graduação.

7. Qual área você estuda ou se formou? Ciências agrárias; Ciências biológicas; Ciências exatas e da terra; Ciências humanas, letras e arte; Ciências da saúde; Ciências sociais aplicadas; Engenharias e Outra.

8. Qual sua profissão? (resposta aberta).
} 


\footnotetext{
9. Qual a sua renda familiar? Até 2 salários mínimos, Entre 2 e 4 salários mínimos, Entre 4 e 10 salários mínimos, Entre 10 e 20 salários mínimos e Acima de 20 salários mínimos.

10. Nos últimos dois anos, quantas vezes você visitou algum museu? Esta é a primeira vez, Entre 2 e 5 vezes, Entre 5 e 10 vezes e Mais de 10 vezes.

11. Quantas vezes você já visitou algum museu? Esta é a primeira vez, Entre 2 e 5 vezes, Entre 5 e 10 vezes e Mais de 10 vezes.

12. E o MCC, quantas vezes você já visitou? Esta é a primeira vez, Entre 2 e 5 vezes, Entre 5 e 10 vezes e Mais de 10 vezes.

13. Porque você está nos visitando? Para nos conhecer, por lazer em geral, acompanhando alguém, conhecer nossas novidades, visitar alguma exposição específica, participar de algum evento, realizar estudo/pesquisa ou outros motivos.

14. Quem te acompanha durante a visita? Estou só, cônjuge, família, amigos, grupos organizados e outros.

15. Como ficou sabendo do museu? Redes sociais, TV / rádio / jornal, notícias na internet, site do museu, panfletos, amigos / familiares e outros.
}

Quadro 1 - Perguntas do questionário de pesquisa de públicos do MCC (AMARAL, 2019).

A Figura 1 ilustra algumas telas do software de coleta de dados sobre os visitantes do MCC projetado por Amaral (AMARAL, 2019; AMARAL et al., 2021). Da esquerda para a direita, temos a tela inicial, as telas da primeira e da décima quarta pergunta e a tela de confirmação. Um protótipo das telas deste software foi elaborado com o Adobe XD. Apesar deste protótipo simular a navegação entre as telas, ele não foi capaz de simular todos os comportamentos da interface do sistema. Por exemplo, não foi possível simular a seleção de uma opção de pergunta (marcar um checkbox), nem o comportamento do autocompletar enquanto o usuário digita um texto num campo (opção de resposta "outros", por exemplo). Estas limitações podem influenciar de forma significativa o uso do sistema.

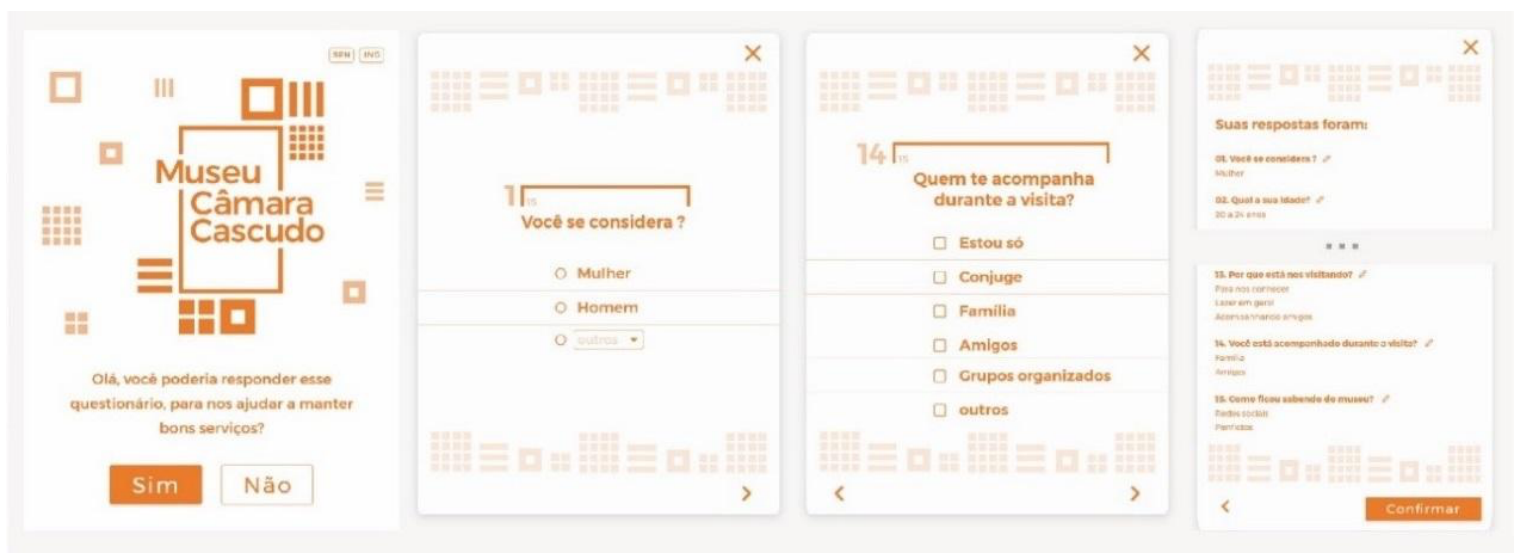

Figura 1 - Exemplos de telas projetadas para a interface do software de coleta de dados dos públicos do MCC.

Para concluir seu processo de design, Amaral (AMARAL, 2019; AMARAL et al., 2021) realizou uma avaliação somativa (BARBOSA; SILVA, 2010) da interface do protótipo utilizando um teste de usabilidade (RUBIN; SHIRK, 1996) com dez pessoas com potencial de visitar o MCC. Ela concluiu que todos os participantes conseguiram preencher o questionário usando o protótipo em 2,04 minutos em média. Alguns participantes tiveram dificuldades em lidar com as limitações do protótipo, mas destacaram o potencial do software para ser utilizado no cotidiano do museu.

\section{Metodologia}

Em continuidade ao trabalho de Amaral (AMARAL, 2019; AMARAL et al., 2021), este trabalho apresenta uma pesquisa exploratória com objetivos de (1) desenvolver (programar) o software projetado e (2) avaliar a viabilidade de uso desta solução por visitantes do MCC, dentro do setor expositivo. Isso é importante para 
compreender como as questões de design podem ser articuladas com as questões de construção da tecnologia, e como ocorre o uso do artefato construído, em contexto real.

O primeiro passo foi estudar a solução de design digital proposta por Amaral. Depois, o software projetado foi programado com a intenção de entregar uma solução tecnológica com as funcionalidades, o processo de interação e a interface propostos no projeto, com o cuidado de articular adequadamente as considerações feitas pela designer. Por fim, o software desenvolvido foi implantado para ser avaliado por um teste de usabilidade in loco (RUBIN; SHIRK, 1996; GOODMAN et al., 2012).

A coleta de dados do teste de usabilidade foi realizada em dois dias: em uma quinta-feira e um sábado de agosto de 2019. Ao serem abordados durante o final de sua visitação no interior do setor expositivo do museu, os visitantes do MCC foram convidados a participar espontaneamente desta avaliação. Depois de ouvir explicações sobre os objetivos da avaliação, eles manifestaram por escrito seu consentimento livre e esclarecido para participar. Todas as pessoas convidadas aceitaram contribuir com o teste de usabilidade.

A Figura 2 mostra o roteiro utilizado no teste de usabilidade composto por três partes: entrevista pré-teste, observação de uso do software e entrevista pós-teste. Cada participante individualmente respondeu às perguntas pré-teste: (1) Você já respondeu questionários online? e (2) Costuma utilizar tecnologias da informação como WhatsApp, e-mail e Facebook? Em seguida, dentro do ambiente expositivo do MCC sendo exposto a condições reais de visitação, o visitante usou o software desenvolvido para preencher o questionário de pesquisa de perfis de públicos de museus. O software foi usado em um tablet Samsung com tela de 10.1 polegadas, modelo SM-T531, com Android 5.0.2, acessando a rede wi-fi disponível gratuitamente aos visitantes do museu. Por fim, ele respondeu às perguntas pós-teste: (1) O que você achou da experiência de preencher este questionário? (2) O que gostou? O que não gostou? (3) Você sentiu alguma dificuldade? (4) Teve alguma dúvida? (5) Tem alguma sugestão de melhoria? e (6) Você achou alguma pergunta constrangedora?

entrevista pré-teste

$\nabla$ Você já respondeu formulários online?

Costuma utilizar tecnologias da informação como WhatsApp, e-mail e Facebook?

observação de uso

do software num tablet

entrevista pós-teste

$\nabla \quad$ O que você achou da experiência de preencher este questionário?

O que gostou? O que não gostou?

Você sentiu alguma dificuldade?

Teve alguma dúvida?

Tem alguma sugestão de melhoria?

Você achou alguma pergunta constrangedora?

Figura 2 - Roteiro do teste de usabilidade. 
O teste de usabilidade foi conduzido por dois avaliadores: um concentrou-se na condução do roteiro com o participante e o outro cuidou principalmente do registro dos dados coletados. As falas dos participantes foram gravadas em arquivos de áudio com um smartphone. A interação com o software desenvolvido foi gravada em vídeo do que apareceu na tela do tablet pelo aplicativo AZ Screen Recorder. Algumas anotações sobre o contexto foram feitas pelos avaliadores durante a observação de uso do software para serem consideradas na análise.

No decorrer da análise dos dados coletados, foram ouvidas as gravações dos áudios e assistidos os vídeos de interação para identificar os seguintes aspectos: (1) quantos usuários conseguiram completar com sucesso o questionário; (2) quanto tempo foi necessário para concluir seu preenchimento; (3) que dúvidas os usuários tiveram; e (4) houve desconforto em responder o questionário.

\section{Resultados}

Os resultados desta pesquisa exploratória estão relacionados à construção do artefato projetado e ao seu uso. Eles estão agrupados e descritos a seguir nesta ordem.

\subsection{Desenvolvimento do Software para Coleta de Dados de Públicos do MCC}

Compreendidos os requisitos definidos por Amaral (AMARAL, 2019; AMARAL et al., 2021), a primeira preocupação foi analisar em quais dispositivos o software seria utilizado no dia a dia do MCC: smartphone, tablet, desktop, dentre outras opções. O museu não dispõe de uma quantidade significativa de dispositivos de um mesmo tipo. Além disso, quando algum deles apresentar defeito, o tempo para reparo tende a ser significativo e até nunca ocorrer. A substituição por novos dispositivos também costuma ser desafiadora por restrições financeiras e burocráticas.

Nesse contexto, o software de coleta de dados de públicos do MCC precisa ser bastante flexível para ser utilizado com qualquer dispositivo que estiver disponível, até para permitir que mais visitantes sejam consultados ao mesmo tempo. Essa flexibilidade é fundamental para que a pesquisa de públicos possa ser realizada de forma contínua sem ser prejudicada por defeitos ou falta de um dispositivo específico. Portanto, o software de coleta de dados de públicos do MCC foi desenvolvido como um sistema web dividido em uma parte cliente e outra parte servidor. A parte cliente pode ser utilizada facilmente em navegadores web de vários dispositivos. Já a parte servidora do software poderia ser hospedada no mesmo servidor web que hospeda o site do MCC, sem exigir nova infraestrutura. Outra vantagem dessa abordagem é manter todos os dados coletados reunidos em um mesmo banco de dados no servidor para facilitar sua utilização futura e manutenção.

A organização dos dados coletados foi outra questão fundamental no desenvolvimento deste software para (1) facilitar análises futuras, (2) viabilizar a evolução do questionário proposto e (3) poder ser utilizado para outras pesquisas de públicos no MCC. Dados em meio digital podem ser facilmente analisados futuramente com apoio de algum software (como planilhas eletrônicas, por exemplo) se estiverem organizados adequadamente. É preciso identificar cada resposta para cada pergunta do questionário fornecida por um visitante em uma data. Isso oferece as condições necessárias para realização de vários tipos de análises com vários objetivos em pesquisas de públicos: cálculos, comparações, geração de gráficos, relatórios, etc.

As perguntas e possíveis respostas do questionário de pesquisa de públicos poderiam ser definidas diretamente nas páginas web do software; por exemplo, programadas diretamente em HTML. Contudo, isso dificultaria a evolução do questionário e o reuso do software em outras pesquisas de públicos. Uma abordagem mais interessante é salvar em banco de dados a definição do questionário, com suas perguntas e possíveis respostas. É mais fácil e rápido editar, acrescentar e remover perguntas e respostas de um 
questionário definido em banco de dados do que definido em páginas web. Essa abordagem também permite utilizar o mesmo software para realizar pesquisas de públicos com novos questionários no futuro apenas atualizando o banco de dados, seja para o próprio MCC ou mesmo para outros museus.

A definição de um questionário no banco de dados possui uma descrição e um conjunto de perguntas. Cada pergunta pode possuir um conjunto de possíveis respostas, quanto for uma pergunta fechada. No momento em que um visitante responder a uma pesquisa de público, sua resposta estará vinculada a determinado questionário contendo um conjunto de respostas a perguntas. A Figura 3 ilustra o modelo de dados (com um diagrama de classes da UML - https://www.uml.org/) utilizado no desenvolvimento do software para pesquisas de públicos do MCC. Este modelo de dados pode ser considerado como parte da arquitetura de informação do software.

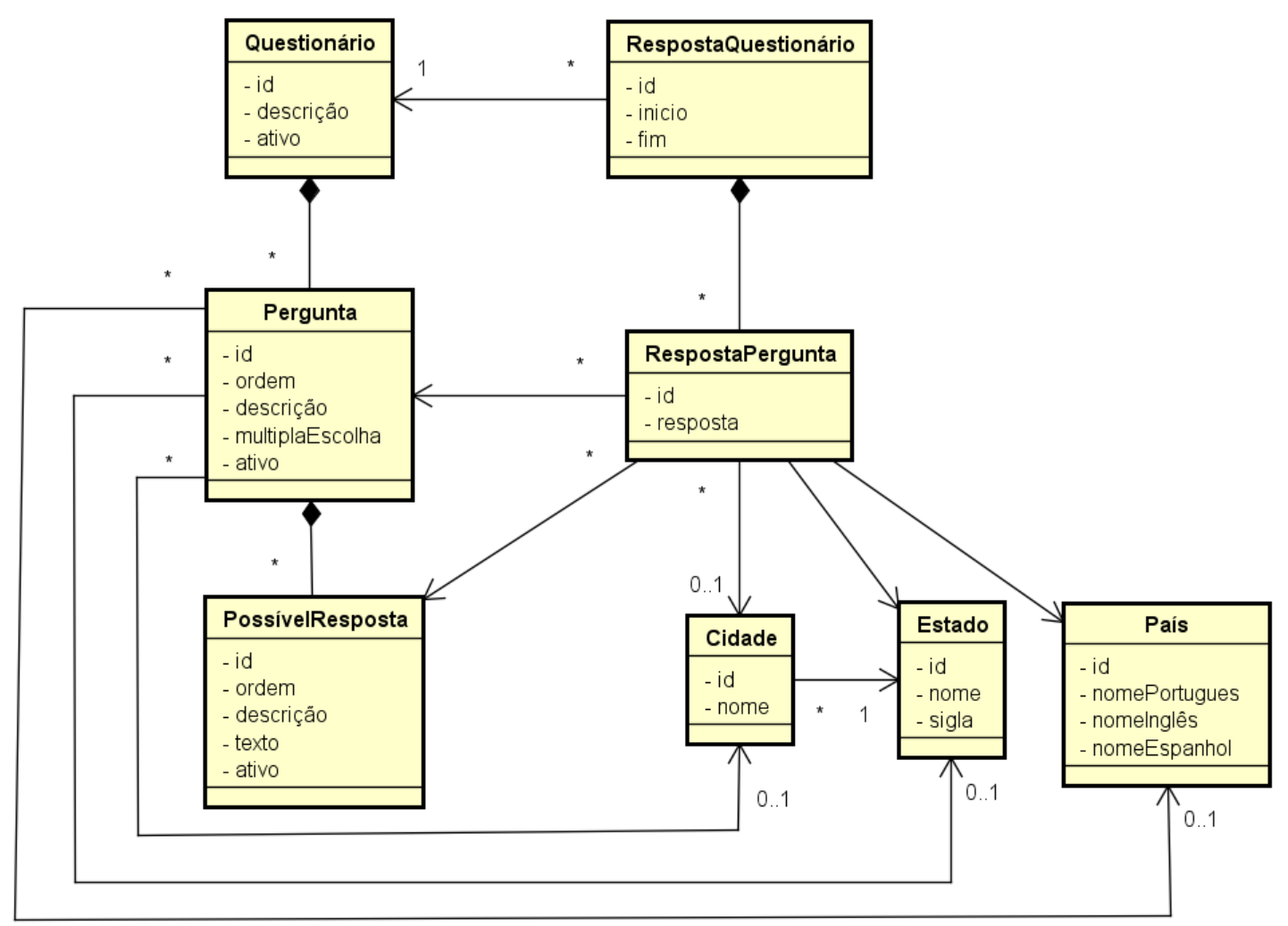

Figura 3 - Modelo de dados do software de coleta de dados de público do MCC.

O banco de dados utilizado foi o MariaDB, em um servidor web XAMPP. A parte cliente do sistema web foi desenvolvida com HTML, CSS e JavaScript, em conjunto com bibliotecas como BootStrap e JQuery. Dentre outras questões, a biblioteca BootStrap facilitou o desenvolvimento de páginas web responsivas, ou seja, que se adaptam melhor a telas de diferentes tamanhos. Isso é importante porque este software será utilizado em diversos dispositivos no MCC. Foi necessário definir tamanhos e posições específicas em CSS para elementos das páginas web nas três principais plataformas: smartphone, tablet e desktop.

As imagens utilizadas foram salvas no formato vetorial SVG para serem redimensionáveis mantendo a qualidade e ocuparem pouco espaço de armazenamento. A quantidade de imagens foi reduzida porque vários elementos visuais decorativos previstos no projeto de Amaral (2019) foram definidos diretamente em HTML e não em imagens específicas. Por exemplo, o cabeçalho das perguntas com a indicação do número da pergunta corrente, da quantidade total de perguntas e a linha decorativa em torno desses números não foi definido como imagem. Na verdade, o cabeçalho da pergunta foi desenhado diretamente em HTML e CSS a 
partir da definição do questionário presente no banco de dados. Deste modo, ao modificar-se o questionário no banco de dados não será necessário alterar o software, nem suas figuras, facilitando a evolução do questionário ao longo do tempo e o reuso do software em outros questionários.

A Figura 4 apresenta exemplos de telas do software desenvolvido neste trabalho, que equivalem às telas projetadas ilustradas na Figura 1. À esquerda da Figura 4 encontra-se uma tela de apresentação do questionário, seguida pelas telas da Pergunta 1 e da Pergunta 14. Por fim, mais à direita, encontra-se uma tela de confirmação com a parte central omitida.

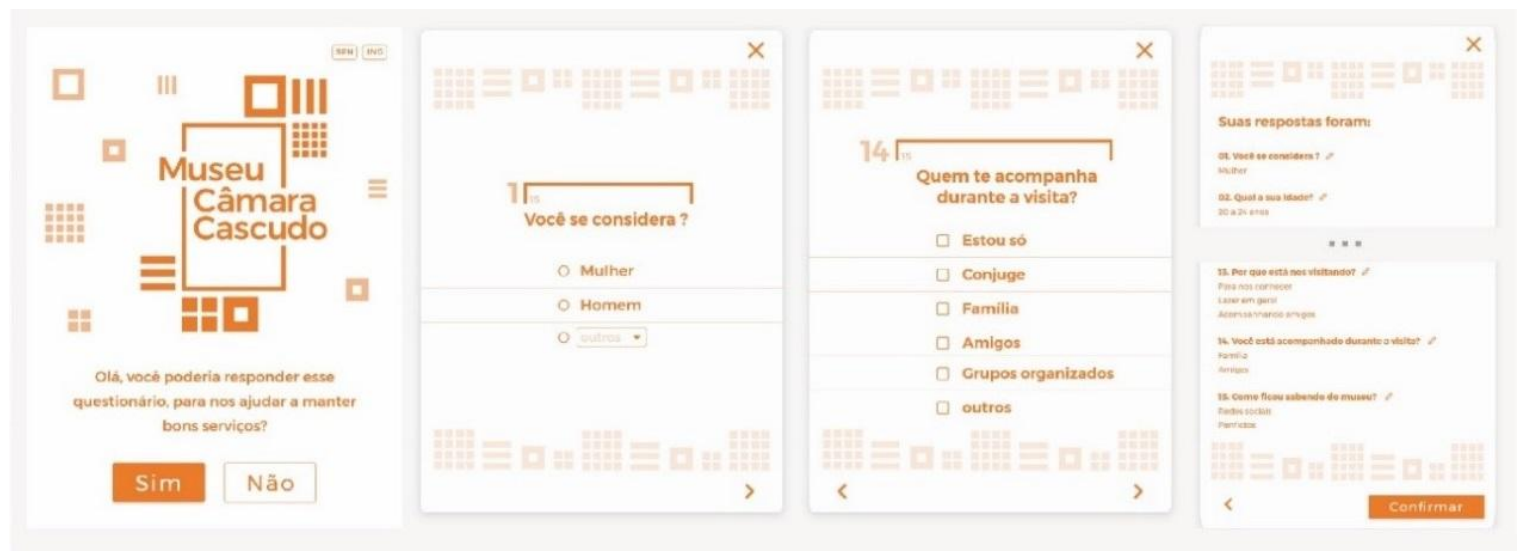

Figura 4 - Exemplo de telas na interface do software desenvolvido neste trabalho.

No final do desenvolvimento do software, ele foi hospedado em um servidor web de testes equivalente ao que hospeda o site do museu. Os programadores realizaram testes funcionais manuais exploratórios (MYERS et al., 2011) via smartphone, tablet e desktop para verificar se a navegação pelas telas de interface estava funcionando como esperado e se o sistema estava salvando as respostas ao questionário como esperado. Esses são testes funcionais básicos típicos na Engenharia de Software (BOURQUE; FAIRLEY, 2014). Problemas na responsividade (configuração automática dos elementos de interface para se adequar ao tamanho da tela) e no autocompletar das caixas de texto foram identificados nestes testes funcionais e corrigidos pelos programadores.

Neste momento, tinha-se um software funcional em condições ideais, sendo utilizado pelos próprios programadores num ambiente com internet estável e com boa velocidade. Seu uso não sofria interferências típicas do ambiente expositivo do museu que podem atrapalhar a atenção do usuário. Como este software se comportaria nas condições reais do Museu Câmara Cascudo? Ele funcionaria satisfatoriamente na internet wi-fi disponível no museu? A dinâmica do ambiente expositivo prejudicaria o preenchimento do questionário? Os visitantes reais do museu teriam dificuldades em utilizar o software e preencher o questionário? Será que os resultados promissores obtidos na avaliação do protótipo de Amaral (2019) se repetiriam no uso do software pelos visitantes reais do MCC naquele ambiente? Questionamentos como esses apontaram para a necessidade de avaliar o uso deste software no MCC e comparar esses resultados com os resultados anteriores de Amaral (2019).

\subsection{Avaliação de Uso do Software para Coleta de Dados de Públicos do MCC}

O teste de usabilidade foi realizado com a participação de 11 visitantes do $\mathrm{MCC}$, destes 3 são homens e 8 são mulheres. A grande maioria costuma usar tecnologia da informação com frequência para participar de redes sociais, ler notícias, ler e-mail e semelhantes. Apenas um visitante alegou não usar nenhum tipo de tecnologia da informação digital e outro utilizava apenas o e-mail. Um pouco mais da metade dos participantes (7 pessoas) já responderam a questionários eletrônicos anteriormente, isto é, já tiveram alguma 
experiência com tarefa semelhante àquela solicitada no teste de usabilidade. Os participantes tinham entre 30 e 59 anos, com pelo menos o ensino superior completo (exceto um participante com ensino fundamental incompleto) e estavam acompanhados na visitação por amigos, família e, alguns deles, crianças pequenas.

Todos os participantes conseguiram concluir satisfatoriamente o preenchimento do questionário usando o software desenvolvido. A falta de conhecimento e a falta de experiência de alguns participantes com o tablet (ambiente Android utilizado por uma tela sensível ao toque) trouxeram algumas dificuldades para avançar na tarefa. Porém, o apoio de um acompanhante mais experiente com a tecnologia foi suficiente para superar rapidamente essas dificuldades. Adultos acompanhados de crianças pequenas conseguiram administrar bem os cuidados com as crianças e o preenchimento do questionário. Eles não apresentaram dificuldades para participar da pesquisa de públicos usando o software desenvolvido. Crianças um pouco maiores inclusive se envolveram nas respostas do questionário junto com os seus responsáveis.

Em média, os participantes levaram 3 minutos (179.7 segundos) para preencher o questionário, com um desvio padrão de 1 minuto e 10 segundos. Quatro participantes (36\%) precisaram de mais tempo do que a média para concluir o preenchimento do questionário. A maioria tinha entre 50 e 59 anos de idade. Todavia, a idade não foi um fator determinante, pois alguns participantes mais jovens também precisaram de mais tempo do que a média e vice-versa. Os adultos acompanhados de crianças não demonstraram desempenho pior do que os demais. A necessidade de ajuda com a tecnologia influenciou algumas vezes, mas também não foi determinante para o tempo de execução ter ficado acima da média. O tempo que cada participante pensou sobre as perguntas para definir suas respostas parece ser a principal razão das diferenças no tempo de conclusão da tarefa de responder o questionário. Algumas pessoas costumam pensar mais tempo do que outras antes de responder. Outras levam mais tempo para ler um texto e lembrar do que sabem a respeito. Essas diferenças são naturais na percepção e cognição humana.

A opinião dos participantes sobre a experiência de participar desta pesquisa de públicos usando o software desenvolvido foi muito positiva. Vários participantes afirmaram que gostaram de usar o software, ainda que tenham tido pouca experiência anterior com a tecnologia. Foi fácil, simples, objetivo e com boa organização visual. Quase todos disseram gostaram de usar o software, mas um deles manifestou ser um desafio porque não estava acostumado a usar um tablet.

Nenhum participante reportou dificuldade após ter concluído o preenchimento do questionário, mesmo aqueles que receberam ajuda para avançar. Isso provavelmente ocorreu porque as eventuais dificuldades foram rapidamente resolvidas e se tornaram pouco significativas. Ninguém verbalizou dúvida sobre como usar o software e sobre as perguntas e opções de resposta quando questionados a respeito.

Um participante sugeriu uma melhoria para a interface relacionadas à eficiência de uso. Na tela de confirmação (mais à direita na Figura 4), o usuário pode corrigir sua resposta a uma pergunta, voltando para a tela da pergunta com sua resposta preenchida (telas do meio na Figura 4). Após a correção da resposta, deveria ser possível voltar diretamente para a tela de confirmação sem percorrer todas as perguntas seguintes novamente. Outra sugestão foi incluir uma pergunta sobre a opinião dos visitantes sobre o pagamento de ingresso para auxiliar na sua manutenção. Atualmente não existe cobrança de ingresso no MCC.

Apenas um visitante manifestou algum constrangimento quando questionado sobre as perguntas realizadas. Ele se incomodou em ter que reconhecer que não conhecia o museu mesmo tendo nascido e morado toda sua vida na cidade onde se localiza o museu. Ninguém manifestou incômodo com perguntas possivelmente delicadas para algumas pessoas como idade e renda familiar, por exemplo. A Tabela 1 apresenta os principais dados coletados dos participantes. 


\begin{tabular}{|c|c|c|c|c|c|c|c|}
\hline & experiência & gostou? & dificuldade? & dúvida? & sugestão? & $\begin{array}{l}\text { pergunta } \\
\text { constrangedora? }\end{array}$ & duração \\
\hline $\mathrm{P} 1$ & & $\operatorname{sim}$ & não & não & não & não & $3 \min 13 s$ \\
\hline $\mathrm{P} 2$ & $\begin{array}{l}\text { achou } \\
\text { interessante }\end{array}$ & & não & não & não & não & $3 \min 16 s$ \\
\hline P3 & $\begin{array}{l}\text { achei ótima. } \\
\text { útil }\end{array}$ & $\operatorname{sim}$ & não & não & não & - & $2 \min 24 s$ \\
\hline P4 & $\begin{array}{l}\text { é bom. } \\
\text { primeira vez } \\
\text { que mexeu }\end{array}$ & $\begin{array}{l}\text { não gostei } \\
\text { porque estou } \\
\text { desinformada } \\
\text { da tecnologia }\end{array}$ & $\begin{array}{l}\text { não, mas teve } \\
\text { ajuda }\end{array}$ & não & não & não & $6 \min 11 s$ \\
\hline P5 & $\begin{array}{l}\text { fácil. } \\
\text { questionário } \\
\text { bom de } \\
\text { responder. }\end{array}$ & $\operatorname{sim}$ & não & não & $\begin{array}{l}\text { pergunta } \\
\text { sobre ingresso }\end{array}$ & não & $2 \min 5 s$ \\
\hline P6 & tranquila & $\operatorname{sim}$ & não & não & $\begin{array}{l}\text { pergunta } \\
\text { sobre ingresso }\end{array}$ & não & $3 \min 25 \mathrm{~s}$ \\
\hline $\mathrm{P} 7$ & boa & $\operatorname{sim}$ & não & não & não & não & $2 \min 45 s$ \\
\hline P8 & $\begin{array}{l}\text { simples, } \\
\text { objetivo, } \\
\text { visualmente é } \\
\text { fácil. }\end{array}$ & $\operatorname{sim}$ & não & não & $\begin{array}{l}\text { ao corrigir } \\
\text { questão, voltar } \\
\text { para tela de } \\
\text { revisão }\end{array}$ & não & $2 \min 51 \mathrm{~s}$ \\
\hline P9 & tranquila & tranquilo & não & não & não & $\begin{array}{l}\text { constrangeu-se } \\
\text { em dizer que foi } \\
\text { ao museu pela } \\
\text { primeira vez } \\
\text { sendo da cidade. }\end{array}$ & $1 \mathrm{~min} 51 \mathrm{~s}$ \\
\hline P10 & ótima & $\operatorname{sim}$ & não & não & não & não & $2 \min 21 s$ \\
\hline P11 & boa & $\operatorname{sim}$ & $\begin{array}{l}\text { não, mas teve } \\
\text { ajuda }\end{array}$ & não & não & não & $2 \min 35 s$ \\
\hline
\end{tabular}

Tabela 1 - Dados coletados dos participantes do teste de usabilidade.

\section{Discussão dos Resultados}

A experiência de desenvolvimento relatada neste trabalho apresentou algumas decisões relacionadas à construção (programação) do software que não haviam sido antecipadas pela designer no trabalho de Amaral (AMARAL, 2019; AMARAL et al., 2021), mas que dependeram bastante de aprendizados obtidos ao longo do processo de design. Conhecimentos sobre os usuários, seus objetivos e sobre o contexto de uso tipicamente adquiridos no processo de design foram muito úteis para se tomar decisões sobre: (1) tecnologias de programação para diferentes plataformas e dispositivos; (2) o modo como os dados foram organizados e armazenados internamente no banco de dados; e (3) a forma de definição no software das perguntas e possíveis respostas do questionário de pesquisa de públicos. O relato feito por Amaral foi além de apresentar a interação e a interface projetadas para o artefato digital. Ele incluiu também o aprendizado sobre o problema de design abordado. Sem isso, as decisões de construção deste artefato provavelmente seriam prejudicadas. 
Situações assim chamam a atenção para o fato de que o trabalho de um designer não deveria se encerrar na definição da interface de um artefato digital. As funcionalidades de um artefato digital, ou seja, os comportamentos de um sistema computacional, também decorrem de decisões de design e deveriam estar integradas ao trabalho do designer na definição da interface. Em decorrência disso, a construção do software também deveria ser coerente tanto com o projeto realizado, quanto com o aprendizado obtido durante $\mathrm{o}$ processo de design. $\mathrm{O}$ trabalho de profissionais de Computação deveria ser bem integrado ao trabalho de profissionais de Design ao longo de todo o processo de desenvolvimento de software. Não parece ser suficiente um designer comunicar apenas a solução de interface digital para um profissional de Computação. O trabalho colaborativo entre profissionais da Computação e de Design deveria compartilhar tanto a solução quanto a compreensão do problema de design. Todo o aprendizado que o designer adquiriu durante o processo de design deve ser considerado no restante do processo de desenvolvimento de artefatos digitais. Problemática semelhante foi discutida por (SILVA, 2010; SILVA; BARBOSA, 2012).

Neste trabalho foi possível observar que o software desenvolvido funcionou de maneira satisfatória em condições reais no museu, sendo utilizado em um tablet com acesso à rede wi-fi disponível no setor expositivo. Isso confirma os testes exploratórios realizados em laboratório e o potencial identificado durante a avaliação somativa de Amaral (AMARAL, 2019; AMARAL et al., 2021).

O contexto de visitação apresenta vários fatores que podem influenciar a participação dos visitantes na pesquisa de públicos, tais como interação com acompanhantes, com outros visitantes do museu e com guias de visitação; além de eventuais expectativas pessoais no momento de visitação (motivação para o lazer, fome, pressa, etc.). Mesmo com toda essa influência, os visitantes do museu observados neste trabalho levaram 3 minutos em média para concluir um questionário com 15 perguntas (12 segundos para cada pergunta, em média). Isso representa quase 1 minuto a mais $(+50 \%)$ do que foi necessário na avaliação do protótipo de Amaral (AMARAL, 2019; AMARAL et al., 2021). Muito provavelmente isso decorre das interferências do contexto do museu e de características pessoais dos participantes. Situações que poderiam ser consideradas como dificuldades para participação dos visitantes em pesquisas de públicos acabaram não se demonstrando significativas, tais como: visitantes com crianças pequenas, desconhecimento das tecnologias da informação utilizadas e pressa para fazer outras coisas.

Este é um resultado muito bom para informações coletadas de um público real e diversificado do museu. Assim sendo, o software desenvolvido tem potencial para viabilizar a condução da pesquisa de públicos do MCC de forma contínua, além de ser flexível com fácil adaptação das perguntas e respostas do questionário para acompanhar a evolução do museu e da sociedade.

Contínua porque o instrumento de coleta é um software que pode ser usado pela quantidade de visitantes que desejar participar da pesquisa de públicos, sem necessidade de novas impressões como um questionário em papel. Além disso, os dados coletados em um software já estão em meio digital. Isso facilita sua análise com apoio computacional (planilha eletrônica, cálculos estatísticos automáticos, geração de gráficos, etc.), principalmente perante o avanço de áreas da Computação como Ciência de Dados e Inteligência Artificial. Essa facilidade de digitalização e outros suportes computacionais são importantes porque diminuem a demanda de mão de obra, de tempo e outros recursos para condução de pesquisas de públicos em museus. Assim, são maiores as chances destas pesquisas serem realizadas com maior frequência e até serem contínuas. Apesar de existir custo de aquisição de dispositivos para utilização do software, esse custo é diluído em todas as coletas de dados realizadas.

Flexível porque a coleta de dados pode ser feita com uma variedade de dispositivos do museu ou dos seus próprios visitantes. Outro aspecto importante para a flexibilidade é a possibilidade de incluir, remover e editar questionários direto no banco de dados. Inclusive adicionando, removendo ou alterando perguntas e possíveis respostas em questionários existentes. Assim, o software automaticamente atualiza o questionário utilizado na pesquisa de públicos sem a necessidade de nova programação. No futuro, é possível desenvolver 
uma interface que facilite essa atualização do banco de dados para (re)definir os questionários de pesquisa de públicos em museus.

As observações de uso realizadas no teste de usabilidade oferecem indícios de que os funcionários do museu que trabalham na recepção e na mediação das visitas possuem papel importante nas pesquisas de públicos. Eles devem estimular os visitantes a participarem da pesquisa, ainda que aparentemente o visitante pareça não ter interesse ou disponibilidade em colaborar naquele momento. Convites educados acompanhados de explicações sobre a importância da pesquisa de públicos para o museu foram capazes de superar algumas barreiras iniciais dos participantes. Os funcionários do museu devem estar atentos a falta de familiaridade e eventuais dificuldades do visitante com a tecnologia utilizada. Eles devem se dispor a auxiliar o visitante com o uso da tecnologia sempre que houver demanda. Eventualmente eles também podem oferecer ajuda espontânea quando identificarem necessidade. Por isso, é importante que os funcionários do museu fiquem atentos aos visitantes durante a coleta de dados.

Os resultados da pesquisa de públicos realizada por meio do software desenvolvido muito provavelmente serão mais significativos quando o tamanho da amostra for maior. Contudo, com uma amostra pequena de 11 visitantes no teste de usabilidade já foi possível iniciar reflexões importantes a ponto de questionar impressões que muitos funcionários do MCC tinham sobre seus públicos. Essas questões são discutidas a seguir com a intenção de explorar o potencial deste software ser usado como uma ferramenta de coleta de dados para pesquisa de públicos em museus, não para apresentar resultados conclusivos de pesquisa de públicos realizada. Ou seja, o foco aqui é discutir sobre exemplos de reflexões que podem ser feitas com o apoio dos dados coletados pelo software e não sobre os resultados específicos obtidos com ele durante o teste de usabilidade.

O MCC tradicionalmente recebe muitas escolas com crianças e adolescentes acompanhados de seus educadores. Alguns funcionários acabam imaginando que o público relevante do museu são os menores de idade. A pequena amostra do estudo apresentado neste trabalho questiona esse pensamento quando apresenta uma faixa etária diversificada: 5 participantes de 30 a 39 anos, 1 participante de 40 a 49 anos e 5 participantes de 50 a 59 anos. Os públicos do MCC se concentram apenas no público escolar? Os visitantes não escolares realmente são pouco significativos e relevantes ao MCC? Os discursos expositivos do MCC são compreensíveis e atrativos para as idades dos públicos do museu?

Como a cidade onde localiza-se o museu recebe muitos turistas e pensava-se que seus moradores não valorizavam esse tipo de espaço cultural, alguns funcionários acreditavam que, além das escolas, o principal público do museu era composto por turistas e o museu quase não recebia pessoas que moravam próximo dele. Contudo, esse pensamento pode ser questionado diante de resultados que indicam a direção oposta: 9 visitantes $(81 \%)$ moram na cidade onde se localiza o museu ou na região metropolitana a que ele pertence; 1 participante (9\%) mora no interior do estado e apenas 1 participante $(9 \%)$ mora em outro estado do país. A quem deveriam ser direcionados eventos e divulgações do MCC? É suficiente direcionar a divulgação do museu para os turistas? É urgente oferecer conteúdo em línguas diferentes do Português?

Alguns funcionários do MCC pensam que o principal público do museu pertence a classes econômicas mais altas. Entretanto, os participantes do teste de usabilidade pertencem a várias classes econômicas: 1 participante tem renda familiar de até 2 salários mínimos; 4 participantes têm renda familiar entre 2 e 4 salários mínimos; 4 participantes têm renda familiar acima de 4 e abaixo de 10 salários mínimos; 2 participantes têm renda familiar a partir de 10 salários mínimos. O museu deveria se apresentar como espaço interessante apenas para classes econômicas mais altas? A população de menor renda teria interesse em frequentar o museu? Como preparar o museu para receber públicos de renda diversificada?

O MCC tem forte tradição nas áreas de Arqueologia, Paleontologia e Etnografia, com boa interação com a comunidade acadêmica. Não era estranho acreditar que o principal público do museu fosse de pessoas 
formadas nestas áreas. Porém, os resultados do teste de usabilidade chamam a atenção para públicos com formação diversificada: 1 participante da área da saúde, 2 participantes de área biológica, 2 participantes das ciências exatas e da terra, 4 participantes de ciências humanas, letras e artes, e 2 participantes de outras áreas. Os discursos expositivos precisam ser técnicos porque o público que frequenta o MCC é técnico? É necessário construir um discurso interdisciplinar que inter-relaciona saberes para acompanhar a diversidade de formação acadêmica dos públicos do museu?

Alguns funcionários do museu acreditam ser importante manter uma mesma exposição aberta por muitos anos. Seguindo esse pensamento e influência de outros fatores, o MCC chegou a ter as mesmas exposições abertas por várias décadas. Essa abordagem não seria problemática se os públicos do museu sempre fossem diferentes (turistas?) e os visitantes não voltassem a visitá-lo várias vezes. Todavia, quando o teste de usabilidade questionou os visitantes sobre quantas vezes eles já visitaram o MCC, foi possível identificar uma certa recorrência na visitação ao museu: 4 participantes visitaram o museu pela primeira vez, 5 participantes estavam na segunda até a quinta visitação ao museu e 2 participantes já tinham visitado o museu mais de 10 vezes. O retorno dos visitantes ao museu é significativo? Será que o público que volta a visitar o museu está recebendo um serviço adequado?

Esses questionamentos e reflexões foram feitos com base em respostas de apenas 11 visitantes durante um teste de usabilidade. Apesar desses resultados não serem suficientes para conclusões sobre os públicos do MCC, o teste de usabilidade relatado neste trabalho aponta para tipos de reflexões relevantes que podem ser motivadas e facilitadas pela disponibilidade dos dados coletados com o software desenvolvido. Uma amostra maior de participantes na pesquisa de públicos provavelmente trará maiores benefícios para a gestão do MCC, principalmente quando for possível identificar, entender e se adequar às mudanças naturais dos perfis dos públicos que visitam o museu ao longo do tempo.

O software apresentado neste trabalho pode ajudar na coleta de dados na pesquisa de públicos do MCC. Com pouca adaptação, ele também pode ser utilizado por outros museus. Entretanto, é importante lembrar que a coleta de dados é apenas uma etapa da pesquisa de públicos em museus. Ainda se faz necessário analisar os dados coletados e gerar consolidações relevantes, por exemplo em formato de tabelas e gráficos. Assim, apesar deste trabalho ser um avanço em relação ao de Amaral (AMARAL, 2019; AMARAL et al., 2021), outros trabalhos ainda serão necessários para apoiar as demais atividades da pesquisa de públicos antes de artefatos digitais conseguirem beneficiar em plenitude essa importante atividade em museus. Quando gestores de museus conseguirem analisar dados de pesquisa de públicos de forma fácil e rápida, eles poderão caracterizar melhor seus públicos, refletir sobre os serviços que os museus estão prestando a esses públicos e ter melhores condições para o museu se comunicar com seus públicos. Consequentemente, suas decisões de gestão podem ser mais adequadas e efetivas.

\section{Considerações Finais}

Amaral (AMARAL, 2019; AMARAL et al., 2021) apresentou o projeto de um software para coleta de dados de pesquisa de públicos para o Museu Câmara Cascudo (MCC). Como continuação, este trabalho apresentou o desenvolvimento (programação) do software projetado e avaliou seu uso in loco por visitantes do MCC.

Além dos requisitos previstos por Amaral, o desenvolvimento deste software considerou outras questões importantes para sua construção: dados estruturados para facilitar análises futuras, responsividade da interface, flexibilidade e possibilidade de reuso do software. As decisões que os desenvolvedores (profissionais de Computação) tomaram na construção deste artefato digital exigiram não apenas a compreensão da solução de interface projetada, mas também a compreensão do problema de design associado. Isso é um indício de que a colaboração entre profissionais de Computação e Design precisa ser maior do que um acordo sobre a definição da interface com usuário do artefato digital. 
O software desenvolvido foi avaliado por um teste de usabilidade com 11 visitantes dentro do setor expositivo do museu usando um tablet. Essa avaliação demonstrou que o software é funcional dentro do ambiente esperado, com dispositivo e rede wi-fi disponíveis no MCC. Todos os participantes conseguiram preencher o questionário por meio do software com sucesso. As poucas dificuldades que surgiram foram pela falta de familiaridade com a tecnologia, em particular sobre o uso do Android em tela sensível ao toque. Essas dificuldades foram rapidamente superadas com ajuda de acompanhante do visitante. O tempo médio para completar o questionário usando o software foi de 3 minutos, um minuto a mais do que na avaliação do respectivo protótipo desenvolvido por Amaral (AMARAL, 2019; AMARAL et al., 2021). Ainda assim, este parece ser um tempo aceitável perante os potenciais benefícios para a gestão do museu.

Os resultados desse trabalho configuram-se, então, como um importante passo para tornar viável a execução contínua de pesquisas de públicos em museus com suporte de tecnologias digitais. Trabalhos futuros devem continuar desenvolvendo artefatos digitais com boa usabilidade que possam oferecer apoio para o restante do processo na pesquisa de públicos em museus, em particular na análise e no relato dos resultados. Também é preciso avaliar futuramente os impactos do uso de artefatos digitais na pesquisa de públicos de museus e suas consequências para a gestão dessas instituições culturais.

\section{Referências}

ALMEIDA, A.M. Os visitantes do Museu Paulista: um estudo comparativo com os visitantes da Pinacoteca do Estado e do Museu de Zoologia. Anais do Museu Paulista, São Paulo, v. 12, n. 1, p. 269-306, 2004.

AMARAL, M.P.F. 2019. Aplicativo para Coleta de Dados de Avaliação de Públicos em Museus. Trabalho de Conclusão de Curso, Bacharelado em Design, Universidade Federal do Rio Grande do Norte.

AMARAL, M.P.F.; SILVA, B.S.; BESSA, O.F.M. Aplicativo para Sondagem de Públicos em Museus. Revista Design e Tecnologia, v. 11, n. 22, p. 116-138, 2021.

BARBOSA, S.D.; SILVA, B.S. Interação Humano-Computador. Rio de Janeiro: Elsevier, 2010.

BORGES, L.C.; CAMPOS, M.D.; RANGEL, M.F. Museologia e patrimônio: uma introdução. Bol. Mus. Para. Emílio Goeldi. Ciênc. hum., Belém, PA, v. 7, n. 1, 2012.

BOURQUE, P.; FAIRLEY, R.E. (eds.) Guide to the Software Engineering Body of Knowledge, Version 3.0, IEEE Computer Society, 2014.

BOYLAN, P.J. Org. Como gerir um museu: manual prático. Brodowski, São Paulo: Associação Cultural de Apoio ao Museu Casa de Portinari, Secretaria da Cultura do Estado de São Paulo, 2004.

BRAGA, G.C. Museus da cidade do Rio de Janeiro: uma análise sobre público e serviços. Dissertação de mestrado, Rio de Janeiro, Universidade do Estado do Rio de Janeiro, 2002.

CÂNDIDO, M.M.D. Orientações para gestão e planejamento em Museus. Florianópolis: FCC, 2014.

COIMBRA, C.A.Q.; CAZELLI, S.; CORRÊA, M.F.N.; Gomes, I.L. Ampliando Audiências: Por Um Museu Menos Excludente. Diálogos de la Comunicación. n. 88, p. 1-21, 2014.

CORREAA, M.F.N. Encantamento e estranhamento. Como moradores e não moradores de Belo Horizonte experimentam o Museu de Artes e Ofícios. Dissertação (Mestrado em Museologia e Patrimônio). Rio de Janeiro: Universidade Federal do Estado do Rio de Janeiro e Museu de Astronomia e Ciências Afins, 2010. 
CURY, M.X. Comunicação e pesquisa de recepção: uma perspectiva teórico-metodológica para os museus. História, Ciência, Saúde - Manguinhos, Rio de Janeiro, v. 12, supl. p. 365-380, 2005.

CURY, M.X. A Pesquisa Acadêmica de Recepção de Público em Museus no Brasil: Estudo Preliminar. Anais do XVI Encontro Nacional de Pesquisa em Ciência da Informação (ENANCIB). João Pessoa, 2015.

CUTRIM, A.C.Y.S. Implantação de Métodos Científicos de Avaliação Contínua da Comunicação Museal. Anais do IV Seminário Internacional Museografia e Arquitetura de Museus, Museologia e Patrimônio, 2014.

DROTNER, K.; SCHRØDER, K.C. Museum Communication and Social Media. New York: Routledge, 2013.

GOODMAN, E.; KUNIAVSKY, M.; MOED, A. Observing the User Experience: A Practitioner: Guide to User Research, 2nd edition, Morgan Kaufmann, 2012.

GUAPO, A.L.G.P.D. Avaliação museológica: estudo de caso - avaliação de exposição permanente do Museu da Ciência da Universidade de Coimbra "Segredos da luz e da matéria". Dissertação (Mestrado em Museologia e Património Cultural) Coimbra: Universidade de Coimbra. 2009.

JUNIOR, N.M.; KUPERMAN, P.S. O visitante do século XXI: uma pesquisa de público do MNBA. Museologia e Patrimônio, v. 5, n. 2, 2012.

KÖPTCKE, L.S. Público, o X da questão? A construção de uma agenda de pesquisa sobre os estudos de público no Brasil. Museologia \& Interdisciplinaridade, v. 1, n. 1, p. 209-235, 2012.

MYERS, G.J.; SANDLER, C.; BADGETT, T. The art of software testing. John Wiley \& Sons, 2011.

PAULA, L.M. Museu de Ciências lugar do público! Um estudo de caso acerca do público espontâneo que visita um museu de ciências no Rio de Janeiro. Dissertação (Mestrado em Ensino em Biociências e Saúde), Instituto Oswaldo Cruz, Rio de janeiro, RJ, 2013.

RUBIN, J.; SHIRK, H.N. Handbook of usability testing: How to plan, design, and conduct effective tests. Journal of Technical Writing and Communication, v. 26, n. 1, p. 97-106, 1996.

SILVA, B.S. O uso de casos na reflexão em ação em atividades de design de IHC. Tese de Doutorado (Doutorado em Informática). Rio de Janeiro: Pontifícia Universidade Católica do Rio de Janeiro, Brasil. 2010 .

SILVA, B.S.; BARBOSA, S.D.J. A conceptual model for HCI design cases. In: Proceedings of the 11th Brazilian Symposium on Human Factors in Computing Systems. p. 209-218. 2012.

SILVA, M.C.; SILVA, J.Z. Perfil dos visitantes do museu de anatomia veterinária da FMVZ/USP: primeiros estudos. Museologia \& Interdisciplinaridade, Brasília, v. 3, n. 6, p. 257-276, abr. 2015.

STUDART, D.C.; MANO, S.; PEREIRA, M. Um Sistema Digital para Avaliação e Registro de Visitas a Museus e Centros de Ciência. Anais do X Reunión de la Red de Popularización de la Ciencia y la Tecnología en América Latina y el Caribe (RED POP - UNESCO) y IV Taller "Ciencia, Comunicación y Sociedad", San José, Costa Rica, 2007. 